\title{
Exploring the case of a local food bank to understand information technology use in government information networks
}

\author{
Joana Carvalho \\ Centro ALGORITMI, University of Minho \\ \& United Nations University (UNU-EGOV) \\ Portugal \\ joanacarvalho87@gmail.com
}

\author{
Rui Dinis Sousa \\ Centro ALGORITMI, University of Minho \\ Portugal \\ rds@dsi.uminho.pt
}

\begin{abstract}
Information technologies are transforming many aspects of society, enabling new solutions to the problems governments are facing. The challenges brought up by the way cities around the world are evolving and growing demand new forms of cooperation among public and private entities. Government Information Networks are a form of organizing such cooperation that aim at achieving sustainable societies while managing to offer good quality of life to citizens and respond to growing community needs and demands. Existing studies on government networks overlooked the role of information technology in the establishment, operation, and management of these networks. This research intends to focus on understanding how information technology is used in Government Information Networks, exploring a case study regarding the Emergency Food Network created in Portugal during the Covid-19 pandemic.
\end{abstract}

\section{CCS CONCEPTS}

- Applied computing $\rightarrow$ Computers in other domains $\rightarrow$ Computing in government $\rightarrow$ E-government

\section{KEYWORDS}

Government Information Networks, Case Study, Information Technology, Emergency Food Network

\section{ACM Reference format:}

Joana Carvalho, Rui Dinis Sousa. 2020. Exploring the case of a local food bank to understand information technology use in government information networks. In Proceedings of the $13^{\text {th }}$ International Conference on Theory and Practice of Electronic Governance (ICEGOV 2020), 23-25 September 2020, Athens, Greece, 4 pages. https://doi.org/10.1145/3428502.3428587

Permission to make digital or hard copies of all or part of this work for personal or classroom use is granted without fee provided that copies are not made or distributed for profit or commercial advantage and that copies bear this notice and the full citation on the first page. Copyrights for components of this work owned by others than ACM must be honored. Abstracting with credit is permitted. To copy otherwise, or republish, to post on servers or to redistribute to lists, requires prior specific permission and/or a fee. Request permissions from Permissions@acm.org.

ICEGOV'20, September 23-25, 2020, Athens, Greece

(C) 2020 Association for Computing Machinery.

ACM ISBN 978-1-4503-7674-7/20/09...\$15.00

https://doi.org/10.1145/3428502.3428587

\section{INTRODUCTION}

Global trends in societies' growth and organization present a new reality that includes megacities [1,2], desertification of rural areas, and ageing population [3], to name a few. This reality brings forth challenges (disparity of opportunities, income inequality, unequal conditions for public service delivery [3], etc.) that affect public confidence in governments [4]. As a consequence, governments (local, regional, national) are impelled to improve their role while accompanying the advancements in information technology (IT) [5] to transform the relationships between government and citizens, businesses, other non-state actors and other arms of government (Electronic Governance - EGOV) [4].

Several authors $[4,6,7,8,9]$ explored whether the current governance model and e-government in place are enough to respond and implement technological solutions that address these challenges. The general argument is that we need stronger institutions and partnerships among institutions, citizens, and other stakeholders [10]. These partnerships would allow the sharing of resources, knowledge, and capabilities available, supported by IT to tackle the needs of smarter societies [8]. Government Information Networks (GIN) are such a form of organizing and partnering [4]. GIN enable governments to embrace the multitude of contexts and actors surrounding each issue, to foster flexibility, to establish collaborative environments, and to pursue articulated actions between government and other organizations and citizens. Despite the attention given so far to GIN in the literature, the role that IT can have in designing, establishing, developing, operating and managing GIN remains quite unexplored.

The recent Covid-19 pandemic brought up several situations where cooperation between governments and other entities 
demanded a coordinated action to face the new challenges that emerged. That is the case of the Emergency Food Network created in Portugal by a non-profit organization to support families in difficulties. As a first step to develop a framework for IT use in GIN, this case will be under study to understand the role of IT in its operation.

The next section (section 2) presents GIN definition, their design, and how IT has been explored in its context. Section 3 presents the case study used to explore the role IT can have in GIN and section 4 offers a discussion on the observations from the case study. Concluding remarks and further work to be developed are presented in section 5 .

\section{GOVERNMENT INFORMATION NETWORKS}

The role that citizens and other stakeholders have been playing in governance activities is leading to a new governance model where decision-making, involvement in wider societal issues [9], and collaboration between different stakeholders is a reality.

Creating, maintaining and managing networks in government is easier now with the available technology that allows a network to efficiently expand and survive despite its size, complexity, and volume of information exchange. IT and networked structures combined with the human capacity to take advantage of the full potential of these technologies is key to enhance characteristics such as productivity, innovation, creativity, and power sharing [11].

GIN are defined by Janowski et al. [4] as "ICT-enabled policy networks, collaboration networks and governance networks". According to the definition, IT is inherent to the network concept in the EGOV context. GIN are complex organisms that imply great coordination and orchestration but from which a cohesive and strong new organization can emerge when created and designed with reality awareness. In these networks, governments may assume a steering role $[7,8,9]$ but the major change networks impart in government structures is the rearrange of power distribution from a centralized to decentralized authority. It is this shift that enables governments to find a balance between greater adaptability and stability [5].

\subsection{Designing Government Information Networks}

Designing networks is in itself a challenge that must follow some core aspects: (1) the selection of network partners is of extreme importance for the availability of resources and existence of harmony amongst members; (2) the network must have a shared goal which will designate its objective; (3) the governance model must be defined and explicit to all network members; (4) the different actors in the network are clearly identified as well as the coordination process; and (5) processes to achieve the intended goals are specified [7, 9].

Particularly for GIN operation to be successful, besides the explicit exposure of the aforementioned aspects, a set of mechanisms and values must be in place to enable harmonious work and facilitate network functioning. These include [6]: (1) the voluntary cooperation of all actors and willingness to let go of individual goals that are not coherent with the network objective (actors believe in the network); (2) conflict resolution must be in place as well as contracts that attend to each actor's apprehensions; (3) the shared vision must be institutionalized in every participating organization for it to have lasting impacts and for individuals to feel involved in the interaction process; (4) incentive design must be in place to cater for each actor's interests since different motivations is what makes the network diverse; (5) change management must be taken seriously and change mechanisms have to be in place since the beginning to avoid network destruction. The network is composed of a network of actors and a network of information and that a lack of match between them results in coordination problems.

\subsection{The role of information technology}

By definition, GIN are established, operated, managed and sustained by IT which is the backbone of these networks. IT constitutes the technical and organizational infrastructure dimensions that facilitate network cooperation, control, coordination, communication, and accountability [7, 11]. From a more informational perspective, due to their distributed and public nature, open data and interoperability [9] are crucial operational aspects of GIN.

IT infrastructures, resources and operational knowledge are assumed to be in place in government operations. However, although most governments have gone through a digitization process, few have the capacity in place to promote networked governance as this can only be achieved in later stages of EGOV development [12]. Only half of the UN Member States have gone beyond digitization [13] to enable contexts of networked governance.

Therefore, the authors believe there is a need from practitioners and a gap in research for a prescriptive framework for the use of IT in the establishment, operation and management of GIN to help and guide governments in GIN design and maintenance. Existing frameworks on governance networks [4, 9] characterize GIN but do not explicitly address the role of IT, and the same is valid for design recommendations available. Thus, a relevant question to explore is What is the role IT has in GIN?

\section{THE EMERGENCY FOOD NETWORK}

The Portuguese Federation of Food Banks, in the early times of the Covid-19 pandemic, realized that many families would find themselves in tough situations. Many people were put on layoff, got fired, or got infected with Covid-19, making it impossible to provide for themselves or their families. In line with the Food Banks mission to avoid waste and bringing it to those in need, a response to identify these families and offer some support was put in place. Besides, funding and donations were requested to the private sector that raised to the occasion.

The Federation named the initiative Emergency Food Network and consulted the 21 Portuguese Food Banks to know which were available to integrate and collaborate. This article takes a closer look at the case of the Braga Food Bank which is an intermediary 
Exploring the case of a local food bank to understand information technology use in government information networks

in the network. Its role was to create a network of partnerships at the local level that would facilitate an emergence response to those in need.

The Braga Food Bank acts in the entire district of Braga (Portugal) including approximately 1 million people distributed by 14 municipalities (Figure 1). Food Banks do not provide goods directly to families. They work in close proximity with partner institutions and non-profit organizations that in turn evaluate, select, and support families in need from their area of action. The area of action can be the municipality or civil parishes within the municipality.

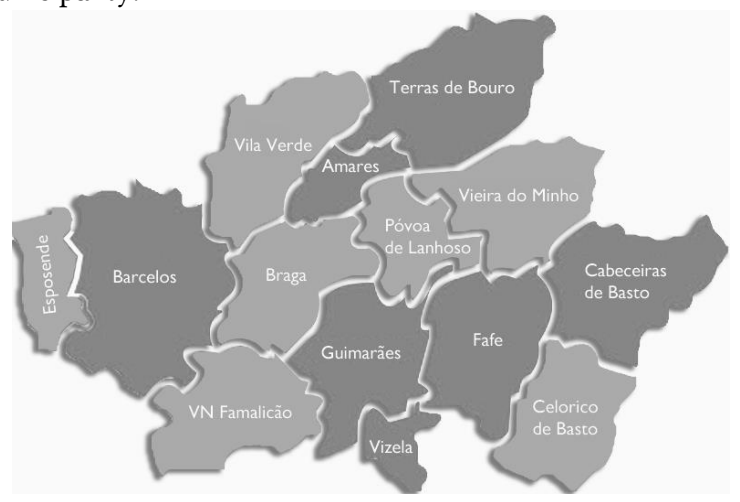

Figure 1 - Braga district representing its 14 municipalities. Retrieved from https://distritaldebragapsd.wordpress.com

When the Portuguese government declared the state of emergency on the $18^{\text {th }}$ of March, most of the partner entities closed operations, leaving many families that counted on their help in need. Adding to the ones that found themselves without jobs, it was expected a great number of people asking for help. From the $20^{\text {th }}$ of March to the $20^{\text {th }}$ of June, the Braga Food Bank answered 1017 requests of help from the Emergency Food Network, corresponding to 3227 persons (Figure 2). During 2019, the Braga Food Bank had helped 39290 persons through 291 institutions.

The process of the Emergency Food Network begins with someone filling a Google Form asking for help. The requests are treated by the Portuguese Federation of Food Banks who exports the form values to an excel file, divides the requests according to district and then, using this division, puts the requests in several Google Sheets. Each Google Sheet is shared with the Food Bank responsible for that district that analyzes each request, contacts the partner entity from that area via email or phone and signals the case as forwarded. Additional information useful for resolution and closure can be registered regarding each case for operations control at a national level.

The greatest difficulty faced by the Braga Food Bank was to find partner organizations that could cooperate during these times. After contacting most of the 291 non-profits with which the Food Bank usually works, it was noticeable the lack of resources to manage a coordinated help. The Braga Food Bank turned to local governments (municipalities and civil parishes) in search of partnerships. For most municipalities it was relatively easy to
ICEGOV 2020, 23-25 September 2020, Athens, Greece

establish partnerships with non-profits still in operation whilst for others it was necessary several online meetings with the local government to make them realize they were accountable for citizens and as such, had to take responsibility and action in a crisis situation.

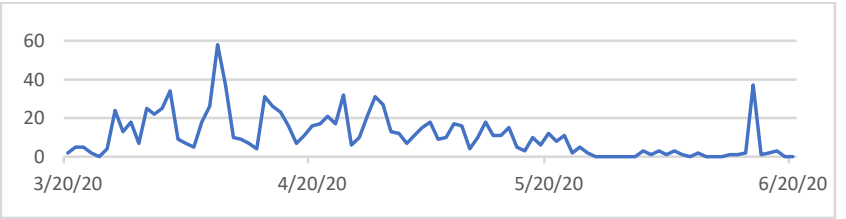

Figure 2 - Requests for help to the Emergency Food Network (Braga district, March 20 ${ }^{\text {th }}-$ June $20^{\text {th }}$ )

\subsection{Interacting with the network partners - challenges and outcomes}

Collaboration with most of the network partners, either nonprofits or local government entities, went smoothly. Something that was common to almost every partner institution was the detection of duplicate requests arriving from different places. It was quickly noticeable that a system was necessary to cross check the multiple requests being made directly by people in need, by independent citizen organizations created to help during the pandemic, and by government institutions.

In one of the municipalities (M1), partnerships began only with civil parishes. Unfortunately, in this case, the proximity between the civil parish representatives and citizens, which the Food Bank usually highlights as something positive, turned out to have a negative effect. Representatives refused to help people they knew and became very judgemental. A new partnership had to be established with an organized citizens movement.

In another municipality (M2), where partnership was established with the city council, the creation of the network was praised and local government representatives were grateful because "the network helped us to identify and help families in need which we would not have the opportunity to know about".

The M3 municipality was the most challenging to manage and operate. Due to the great number of requests submitted, partnerships had to be established with each individual civil parish and the city council to provide resources or help in the network operation. At some point requests that were sent to civil parishes were being forwarded to the city council which in turn forwarded them to a large non-profit organization in the city. That non-profit organization would then contact the Braga Food Bank asking for help, making full circle of the requests. Local social security institutions had to be involved to support civil parishes and cross check requests. The city council ended up recognizing the unpreparedness to deal with the situation in terms of both human resources and IT infrastructures to manage coordinated efforts.

\subsection{Characterizing the network}

The Braga Food Bank case is part of a larger informal network acting at a national level, created in the context of a crisis situation 
to solve a problem, joining autonomous but interacting agents pursuing a common goal [4].

This is a case where the network initiative was launched by a non-profit organization and government did not play the steering role. When initiated by non-state actors, challenges may arise in getting government to support the initiative [8]. This was true for most cases of local government partnership. Besides, because of its initial ad-hoc creation, most of the core aspects and mechanisms mentioned in section 2.1 were not in place and were being established in the course of action. Apart from the objective of the network, which was clear to all participants from the start, and incentives in the form of food donations from the Food Bank to participating institutions to distribute to those in need, all other aspects were later defined. Most difficulties emerged in the agreement of the coordination process and clear definition of the governance model that could be accepted by government institutions.

From an IT perspective, the following roles were identified: 1) communication between entities, 2) information sharing, 3) coordination of action between different entities, 4) information analysis.

\section{DISCUSSION}

Although the Emergency Food Network was an initiative launched by a non-profit organization, it ended up being accepted and fostered by local government entities with successful results. Besides, the network led local authorities to realize the benefits of implementing government networks and the need for IT preparedness to coordinate and manage network operations. This case suggests that non-profit organizations can give an important contribution when working in partnership with governments.

The information flow in the network is a bit fuzzy and technology use falls short of its capabilities. While this was expected to happen when working with non-profit organizations [14], government institutions which have passed the digitization phase, should be able to establish and operate a network with the available technology. For these reasons, the authors believe in the usefulness of a prescriptive framework for IT usage in GIN, for which the case was useful to identify IT needs in the network context.

\section{CONCLUSION}

Society is urging for new governance models that are able to answer and respond to the growing complex challenges that governments face. Governments no longer have the resources and capabilities to face societal problems without involving citizens, the private sector, non-profit organizations, etc. A common model emerges: the creation of networks of collaboration with state and non-state actors to tackle the complex issues of societal living, supported in IT - Government Information Networks. These are somewhat disruptive to hierarchical government functions and force governments to assume a different role in governance, orchestrating and maintaining such networks.

This case study regarding the Emergency Food Network established in Portugal during the Covid-19 pandemic was analyzed from a network and a technology perspective. Both the literature and case analysis bring forth research questions worth mentioning. What are the different roles IT can have in the design, development and management of government networks? What policy recommendations can be made to help governments to create and support networks from an IT perspective?

In future work, this research will evolve to get a deep understanding of the use of IT in GIN. These are the first steps for the development of a prescriptive framework to harness the potential and foster adequate use of IT enabling cooperation between governments and other participants to the well-being of society.

\section{ACKNOWLEDGEMENT}

This paper is partly supported by the project "SmartEGOV: Harnessing EGOV for Smart Governance (Foundations, methods, Tools) / NORTE-01-0145-FEDER-000037", supported by Norte Portugal Regional Operational Programme (NORTE 2020), under the PORTUGAL 2020 Partnership Agreement, through the European Regional Development Fund (EFDR).

\section{REFERENCES}

[1] The World Bank. 2013. Megacities: what does the future hold?. Retrieved from http://www.worldbank.org/en/news/feature/2013/09/18/megaciudadesamerica-latina

[2] UNDESA (United Nations Department of Economic and Social Affairs). 2018 E-GOVERNMENT SURVEY 2018 - Gearing e-government to support transformation towards sustainable and resilient societies. New York.

[3] António Tavares, Delfina Soares, and Elsa Estevez. 2016. Electronic Governance for Context-Specific Public Service Delivery. In Proceedings of the 9th International Conference on Theory and Practice of Electronic Governance (ICEGOV2016), March 1-3, 2016, Montevideo, Uruguay. 135-138. doi: $10.1145 / 2910019.2910110$

[4] Tomasz Janowski, Theresa A. Pardo, and Jim Davies. 2012. Government Information Networks - Mapping electronic governance cases through public administration concepts. Gov. Inf. Q. 29, SUPPL. 1(2012), S1-S10. doi: 10.1016/j.giq.2011.11.003.

[5] Cancan Wang, Rony Medaglia, and Lei Zheng. 2018. Towards a typology of adaptive governance in the digital government context: The role of decisionmaking and accountability. Gov. Inf. Q. 35, 2 (April 2018), 306-322. doi: 10.1016/J.GIQ.2017.08.003.

[6] Joydeeo Guha and Bhaskar Chakrabarti. 2014. Making e-government work: Adopting the network approach. Gov. Inf. Q., 31, 2 (April 2014), 327-336. doi: 10.1016/J.GIQ.2013.11.008.

[7] Marijn Janssen and Elsa Estevez. 2013. Lean government and platform-based governance-Doing more with less. Gov. Inf. Q., 30 (January 2013), S1-S8. doi: 10.1016/J.GIQ.2012.11.003.

[8] Adegboyega Ojo and Sehl Mellouli. 2018. Deploying governance networks for societal challenges. Gov. Inf. Q., 35, 4 (October 2018), S106-S112. doi: 10.1016/J.GIQ.2016.04.001.

[9] Gabriela Viale Pereira, Peter Parycek, Enzo Falco, and Reinout Kleinhans. 2018. Smart governance in the context of smart cities: A literature review. Inf. Polity, 23, 2 (June 2018), 143-162. doi: 10.3233/IP-170067.

[10] OECD.2014. Recommendation of the Council on Digital Government Strategies. Public Gov. Territ. Dev. Dir., vol. July, p. 12, 2014.

[11] Manuel Castells. 2004. Informationalism, networks, and the network society: a theoretical blueprint. Edward Elgar Publishing.

[12] Tomasz Janowski. 2015. Digital Government Evolution: from Transformation to Contextualization. Gov. Inf. Q., 32, 3 (2015), 221-236. doi: 10.1016/j.giq.2015.07.001.

[13] Tomasz Janowski. 2016. Implementing Sustainable Development Goals with Digital Government - Aspiration-capacity gap. Gov. Inf. Q., 33, 4 (October 2016), 603-613. doi: 10.1016/j.giq.2016.12.001.

[14] John Taylor and Eleanor Burt. 2005. Managing trust, generating risk: Incorporating the voluntary sector in UK e-Government. Inf. Polity, 10, 1-2 (2005), 25-35. doi: 10.3233/ip-2005-0067. 